\title{
Should Intermittent Mandatory Ventilation Be Abolished?
}

\author{
Robert M Kacmarek PhD RRT FAARC and Richard D Branson MSc RRT FAARC
}

\author{
Introduction \\ The Beginning \\ Pro: Yes, IMV Should Be Abolished \\ Liberation From Ventilatory Support \\ IMV and Acid-Base Balance \\ Work of Breathing \\ Asynchrony \\ Use of IMV \\ Pro Summary: Abolish IMV \\ The Con Position \\ A Question of Intent \\ The Importance of Spontaneous Breathing \\ Liberation From Mechanical Ventilation \\ Acid-Base Balance \\ The Work of Breathing \\ Asynchrony \\ Use of IMV \\ Outcomes \\ Conclusions
}

\begin{abstract}
Intermittent mandatory ventilation (IMV) was introduced nearly 50 years ago. Despite the initial fanfare and early adoption by many, the role of IMV continues to be questioned. The use of small tidal volumes complicates the application of IMV, and issues with work of breathing, weaning and lack of clear advantages have many calling for a moratorium on its use. Spontaneous breathing, however, has a number of salutatory effects on gas exchange, the distribution of ventilation, and hemodynamics. These issues will be explored in light of a growing body of evidence. Key words: Mechanical ventilation, intermittent mandatory ventilation, synchronized intermittent mandatory ventilation, asynchrony and work of breathing. [Respir Care 2016;61(6):854-866. (C) 2016 Daedalus Enterprises]
\end{abstract}

\section{Introduction}

Intermittent mandatory ventilation (IMV) was first described in 1971 for use in pediatric patients by Kirby et al ${ }^{1,2}$

Dr Kacmarek is affiliated with the Department of Anesthesiology, Harvard Medical School, and Department of Respiratory Care, Massachusetts General Hospital, Boston, Massachusetts. Mr Branson is affiliated with the Department of Surgery, University of Cincinnati, Cincinnati, Ohio.

Dr Kacmarek and Mr Branson presented a version of this paper at the and subsequently in 1973 by Downs et $\mathrm{al}^{3,4}$ for use in adults. IMV is a mode of ventilation where intermittent mandatory breaths are delivered at clinician-defined intervals, and between these mandatory breaths, the patient can breathe spontaneously or with pressure-supported breaths. ${ }^{5}$

\footnotetext{
54th ResPiRATORY CARE Journal Conference, "Respiratory Care Controversies III," held June 5-6, 2015, in St Petersburg, Florida.

Dr Kacmarek has disclosed relationships with Covidien, Orange Medical, and Venner Medical. Mr Branson has disclosed relationships with Bayer, Meiji Pharmaceuticals, Medtronic, Mallinckrodt, Phillips, and Ventec.
} 


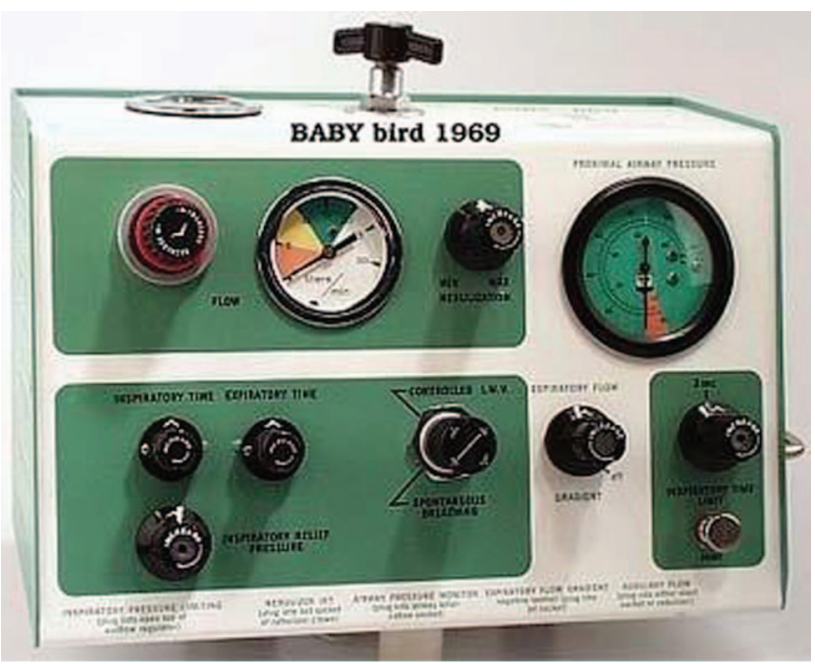

Fig. 1. The first pediatric intermittent mandatory ventilation ventilator, the Baby Bird.

The initial pediatric application was associated with the development of a ventilator using various Bird Corporation parts, which was eventually referred to as the Baby Bird (Fig. 1). ${ }^{1,2}$ For adults, IMV did not initially result in a commercial product but an approach to modify existing ventilator circuits to allow spontaneous breathing between mandatory breaths (Fig. 2). ${ }^{3,4}$ The question being addressed in this pro/con discussion is: Has the time come for IMV to be retired from the list of available modes of ventilation, since other modes perform at least as well as IMV, there are no documented advantages to the use of IMV, and there are potential disadvantages?

\section{The Beginning}

At the time that IMV was introduced into adult mechanical ventilation, the only ventilators available for use in the ICU were intermittent positive-pressure breathing type pressure targeted ventilators and ventilators with volume control designed to only provide controlled mechanical ventilation. ${ }^{6}$ Controlled mechanical ventilation on these units did not function as today's ICU ventilators. There was no possibility of the patient triggering a breath. ${ }^{6,7}$ Although many used intermittent positive-pressure breathing devices to provide continuous ventilatory support, the majority of these applications failed. Thus, the primary ventilators only provided controlled

Correspondence: Robert M Kacmarek PhD RRT FAARC, Respiratory Care, Warren 1225, Massachusetts General Hospital, 55 Fruit Street, Boston, MA 01460. E-mail: rkacmarek@partners.org. Richard D Branson MSc RRT FAARC, University of Cincinnati, 231 Albert Sabin Way, ML \#0558, Cincinnati, OH 45267. E-mail: Richard.branson@uc.edu.

DOI: $10.4187 /$ respcare. 04887

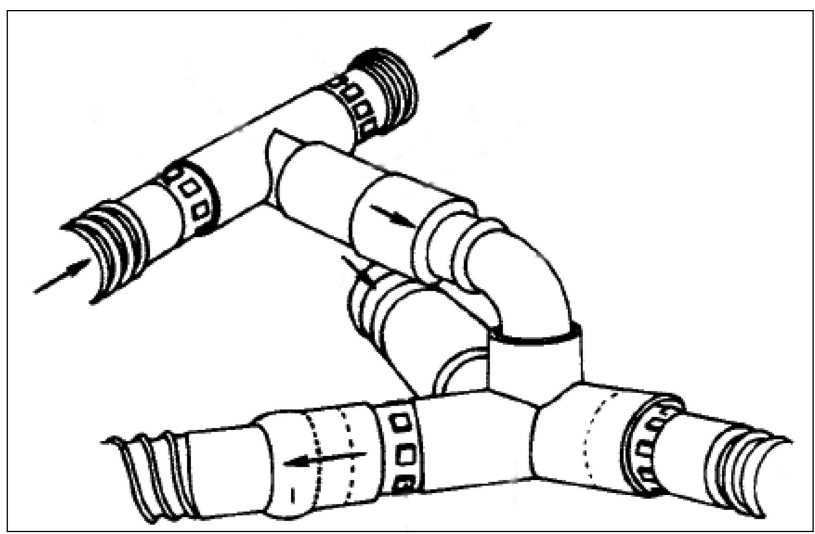

Fig. 2. Assembly used to convert a standard ventilator to an intermittent mandatory ventilation circuit. A high flow of gas moves across the Y-piece of the ventilator circuit. The 2 circuits are separated by a one-way valve only allowing flow into the ventilator circuit by active patient inspiration. From Reference 3, with permission.

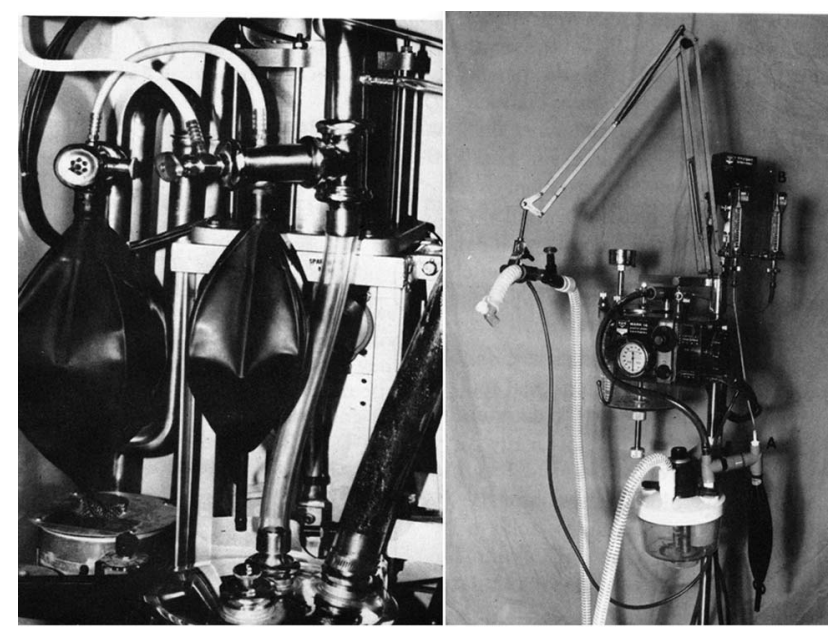

Fig. 3. Emerson post-operative ventilator (left) and Bird ventilator (right), each with an intermittent mandatory ventilation circuit added. From Reference 6.

ventilation. As a result, patients either had to conform to the ventilator output as set by the clinician or be sedated and frequently paralyzed in order to tolerate ventilatory support. There was a need to provide some method of allowing the patient to interact with the ventilator in a more synchronous manner, and IMV filled that need. As a result, almost every ventilator on the market was refitted to allow the application of IMV (Fig. 3). Over time, manufacturers incorporated IMV into adult ventilators with volume control mode in the form of synchronized IMV (SIMV). ${ }^{8}$ With this approach, mandatory breaths were synchronized to the patient effort. ${ }^{5}$ The first ventilator that allowed assist-control ventilation (continuous mandatory ventilation [CMV]) was the Puritan-Bennett MA-1, introduced in the late 1960s.6,7 The final step in the developmental process of IMV occurred with the introduction of the 
Servo 900C, which included pressure support ventilation (PSV). ${ }^{9}, 10$ With PSV, the spontaneous breaths of the patient could be supported, and eventually the mandatory breath could be set as either a pressure-controlled or volume-controlled breath. Over the years, there have been numerous case series $^{11-15}$ supporting the use of SIMV but, as with many modes of ventilation, little evidence supporting an advantage of IMV over currently available modes of ventilation.

Today there are numerous ventilators that allow intimate patient ventilator interaction using a variety of ventilator modes, all of which have at least the potential of providing as much or more synchrony at a much lower patient work of breathing. In the following sections, it will be demonstrated that IMV lengthens the time of mechanical ventilation, provides no advantage over continuous mandatory ventilation in maintaining patient's acid/base balance, does not provide ventilatory support at a lower work of breathing, and does not result in a greater level of synchrony than other modes of ventilatory support.

\section{Pro: Yes, IMV Should Be Abolished}

\section{Liberation From Ventilatory Support}

Esteban et $\mathrm{al}^{16}$ and Brochard et al ${ }^{17}$ published landmark studies during the 1990s demonstrating that IMV was the poorest approach to determining whether patients are ready for ventilator discontinuation. In both of these studies, subjects who initially failed a spontaneous breathing trial were randomized to IMV, PSV, or a spontaneous breathing trial as an approach to determine readiness for ventilator discontinuation. Specific protocols were defined for each approach. With the spontaneous breathing trial approach, subjects had to successfully complete $2 \mathrm{~h}$ of spontaneous breathing. With PSV, they had to sustain spontaneous breathing at either $8 \mathrm{~cm} \mathrm{H}_{2} \mathrm{O}$ for $24 \mathrm{~h}^{17}$ or $5 \mathrm{~cm} \mathrm{H}_{2} \mathrm{O}$ for $2 \mathrm{~h},{ }^{16}$ and with IMV, they had to sustain ventilation with a rate of 4 breaths/min for $24 \mathrm{~h}^{17}$ or 5 breaths/min for 2 h. ${ }^{16}$ In both studies, the number of days to successful liberation was significantly greater with IMV than with PSV or the spontaneous breathing trial. Subsequent studies of weaning and the use of therapist-driven protocols excluded the use of IMV as a possible approach. ${ }^{18-24}$ Ventilator discontinuance guidelines do not recommend the use of IMV as an approach to assessing patient readiness for ventilator liberation. ${ }^{25}$ The most probable reason for these outcomes was that low-level IMV requires higher patient effort during both the mandatory and spontaneous breaths than other approaches to ventilatory support.

\section{IMV and Acid-Base Balance}

One of the issues that had been argued for the superiority of IMV over CMV is the ability of IMV to better

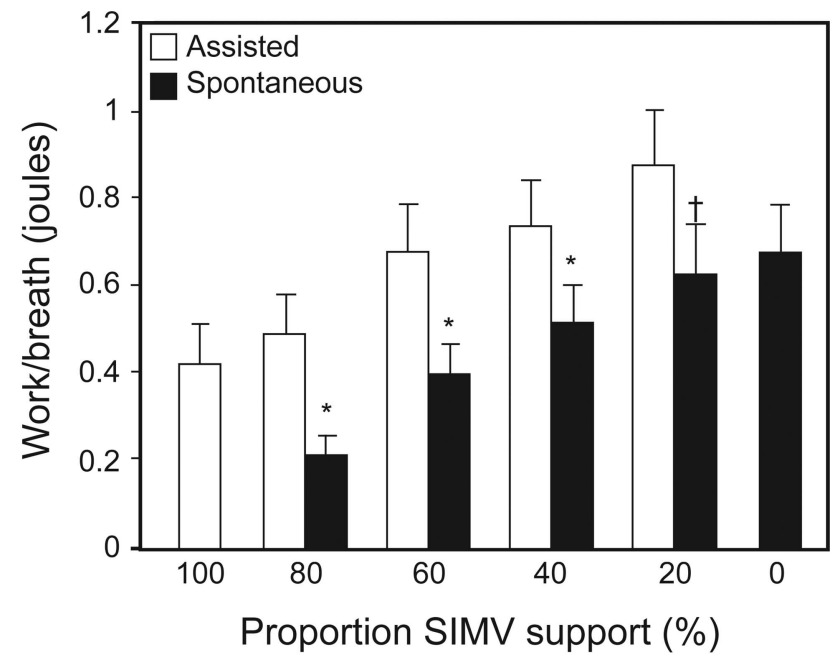

Fig. 4. Mean inspiratory work of breathing during assisted breaths and spontaneous breaths across the spectrum of ventilatory support continuous mandatory ventilation (100\%) to CPAP (0). At each level of synchronized intermittent mandatory ventilation (SIMV), the work of breathing increased; however, the work during the assisted breaths was higher than during the spontaneous breaths. Bars indicate SE. ${ }^{*} P<.01$; $† P<.05$. Adapted from Reference 28.

maintain a patient's acid/base balance. This was reported not to be so by Hudson et al. ${ }^{26}$ In 36 subjects, they compared acid/base balance during IMV and CMV and found no clinically important differences in $\mathrm{pH}$ or $\mathrm{P}_{\mathrm{aCO}}$ regardless of the presence or absence of brain injury. They suggested that although minute ventilation was lower during IMV, carbon dioxide production was increased. Therefore, the $\mathrm{pH}$ and $\mathrm{P}_{\mathrm{aCO}}$ did not change.

\section{Work of Breathing}

Patients receive mechanical ventilation to reduce their work of breathing. However, it has been shown that as the IMV rate decreases, not only does respiratory drive increase, but the amount of work performed by the patient during both spontaneous and mandatory breaths increases. ${ }^{27-32}$ Weiss et $\mathrm{al}^{27}$ compared respiratory drive and timing in 7 subjects requiring ventilatory support but capable of breathing spontaneously for sufficient time to complete their study. They found that as the IMV rate was decreased, respiratory timing was not altered, but ventilatory drive increased as measured by peak inspiratory flow and $\mathrm{P}_{0.1}$.

Marini et $\mathrm{al}^{28}$ showed in subjects with COPD receiving ventilatory support that, as the support provided by mandatory breaths decreased, the work performed by the subject increased not only in the unsupported spontaneous breaths but also during the mandatory breaths. Figure 4 illustrates these results. Note that all subjects began the 


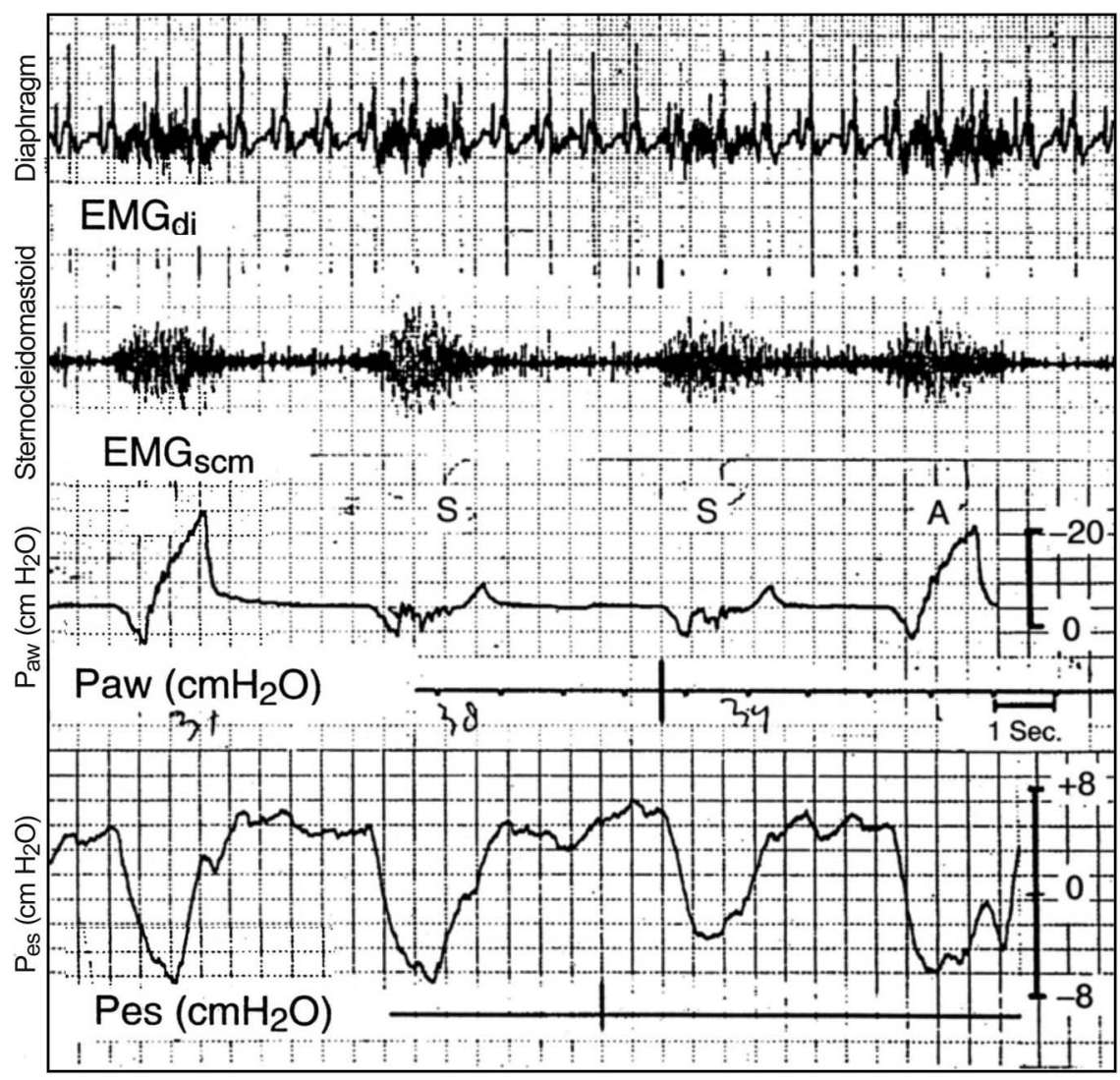

Fig. 5. Electromyograms of the diaphragm and of the sternocleidomastoid muscles, showing similar intensity and duration of electrical activity in successive assisted (A) and spontaneous (S) breaths. $P_{a w}=$ airway pressure; $P_{\text {es }}=$ esophageal pressure; $E M G_{d i}=$ electromyographic signal from the diaphragm; $\mathrm{EMG}_{\mathrm{scm}}=$ electromyographic signal from the sternocleidomastoid muscle. From Reference 29, with permission.

trial on volume control, but after a period of stabilization and measurement, the IMV rate was decreased from $100 \%$ (CMV) to 80, 60, 40, and 20\% IMV mandatory rate and then to CPAP. As the mandatory rate decreased, patient work during the spontaneous breaths increased, but unexpectedly, the work doing the mandatory breaths also increased to a similar extent.

Imsand et $\mathrm{al}^{29}$ studied the neuromuscular output of subjects weaning from ventilatory support who were being managed in volume-targeted IMV. Only when the mandatory rate represented $>60 \%$ of the total support did the neuromuscular output decrease. At lower mandatory rates, there was no difference in electromyographic activity of the respiratory muscles and the $\mathrm{P}_{0.1}$ between mandatory and unsupported spontaneous breaths. Figure 5 shows the electromyographic signal from the diaphragm $\left(\mathrm{EMG}_{\mathrm{di}}\right)$, the electromyographic signal from the sternocleidomastoid muscle $\left(\mathrm{EMG}_{\mathrm{scm}}\right)$, and airway pressure and esophageal pressure change reflective of pleural pressure change during both mandatory and spontaneous breaths. Note that this subject is making the same effort during the mandatory breaths (esophageal pressure change and EMG activity) as during the spontaneous breaths. Why would this be the case? It appears that the respiratory center is not able to rapidly differentiate load on the respiratory system breath to breath if the load is changing rapidly and if a low level of mandatory breaths is applied compared with spontaneous breaths. As a result, the respiratory center assumes that the load it should respond to every breath is the greater load. Thus, as the ventilatory load increases during the spontaneous breath, it assumes that the increased load is present in all breaths. This becomes particularly troublesome when the spontaneous unsupported rate is $\sim 50 \%$ or greater than the mandatory rate. Down-regulation of the neuromuscular output during IMV only appears to be large when the mandatory assistance is $\geq 75-80 \%$ of the total assistance. ${ }^{29,31}$

This increased effort is a concern because most apply IMV at the lowest mandatory rate that sustains the patient's gas exchange. However, this rate may be right at the border of fatigue for the patient, preventing the patient from resting and recovering from ventilatory failure. This is probably the explanation for why IMV is the approach to ventilator liberation most likely to result in the longest period of ventilatory support. It is not uncommon to see patients managed with IMV having a set mandatory rate of 
6-12 breaths/min with an overall breathing frequency at least twice this level.

PSV applied to the spontaneous breaths decreases the work of both the spontaneous breaths and the mandatory breaths. ${ }^{33}$ It appears that unloading the spontaneous breath alters the memory phenomenon observed with unsupported spontaneous breaths. ${ }^{34}$ However, adding pressure support changes the concept of IMV. Does the combination of the 2 different gas delivery approaches make it more difficult to liberate patients from ventilatory support? To compensate for the increased work of breathing during the mandatory and spontaneous breaths, SIMV has been used as pressure control of $15 \mathrm{~cm} \mathrm{H}_{2} \mathrm{O}$ for the mandatory breaths and pressure support of $15 \mathrm{~cm} \mathrm{H}_{2} \mathrm{O}$ for the spontaneous breaths. What is the patient receiving: SIMV, pressure control, or PSV? There is no benefit to managing a patient in this manner compared with using PSV or CMV.

Similar data exist in the pediatric literature. Kapasi et al ${ }^{30}$ compared work of breathing during pressure-controlled IMV, pressure-controlled SIMV, PSV, and pressure control in 7 newborns. These children were $31.4 \pm 2$ weeks gestation and $1.49 \pm 0.38 \mathrm{~kg}$. The ventilator settings determined by the managing team were maintained unchanged; all that was changed was the mode in a randomized fashion, each applied for $20 \mathrm{~min}$. They found that the work of breathing was markedly greater during IMV and SIMV than during PSV and pressure control. Beck et al ${ }^{32}$ measured EMG activity and neural timing of mandatory breaths and unassisted spontaneous breaths in preterm infants who were not sedated. They found that the EMG activity was similar regardless of breath type.

\section{Asynchrony}

Recently, increasing emphasis has been placed on asynchrony and its effects on patient outcome..$^{35-40}$ The presence of an asynchrony index (all asynchronous breaths divided by total breaths, triggered, and missed triggered breaths times 100) $>10 \%$ has been shown to be associated with an increased length of mechanical ventilation, ${ }^{35,36}$ ICU stay, ${ }^{35,36}$ and mortality. ${ }^{37}$ Mode of ventilation impacts asynchrony, with greater levels of mechanical assistance resulting in greater levels of asynchrony. ${ }^{38}$ However, until recently, little data on the presence of asynchrony during IMV has been available. Robinson et $\mathrm{al}^{41}$ demonstrated that subjects receiving IMV compared with other modes of conventional ventilation had a higher asynchrony index. Of the 35 subjects studied, 9 (25.7\%) had an asynchrony index $>10 \%$. Subjects were a median age of $47 \mathrm{y}, 77.1 \%$ were male, $16 \%$ had COPD, and their median injury severity score was 22 . As a result of the small sample size, there were no differences in ventilator days, ICU days, hospital days, discharge home, and mortality. However, all of these values trended higher in the group with an asyn- chrony index $>10 \%$. Thus, the lower the IMV rate, the greater the patients' work of breathing, ${ }^{29,31}$ and the higher the IMV rate, the greater the asynchrony index..$^{41}$ Regardless of how one attempts to modify the application of IMV, there are problems associated with its application.

\section{Use of IMV}

Esteban et $\mathrm{al}^{42,43}$ published epidemiologic studies on the worldwide prevalence of modes of mechanical ventilation. In 2000,42 the worldwide use of IMV as a support mode was $7.9 \%$ (United States, $13.9 \%$ ), and its use as an approach to weaning was $6.8 \%$ (United States, $5.1 \%$ ). In 2008, Esteban et $\mathrm{al}^{43}$ indicated that the worldwide use of IMV had decreased to $1.6 \%$. Criticisms of IMV 44,45 appear to be on point in abandoning the use of IMV.

\section{Pro Summary: Abolish IMV}

IMV does not have any clear advantages over any of the other modes of ventilation. Its reason for existence, allowing spontaneous breathing between mandatory breaths, does not exist today. IMV does not improve gas exchange; it does not decrease the work of breathing and asynchrony; and, most importantly, it does not decrease the length of mechanical ventilation when used as an approach to weaning from ventilator support. IMV has helped clinicians to understand mechanical ventilation and patient-ventilator interaction, perhaps more than any other mode of support. IMV has been instructive, but the lessons are learned.

\section{The Con Position}

\section{A Question of Intent}

IMV was introduced in the early $1970 \mathrm{~s}^{1,2}$ as an alternative to CMV. But beyond discussions of work of breathing and reduced weaning times, the emphasis and advantages of IMV can be traced directly to the maintenance of spontaneous breathing. In fact, the majority of the proposed advantages of IMV arise from the positive attributes of spontaneous breathing. These include improved synchrony, a reduction in the need for sedation, prevention of respiratory alkalosis, reduced air-trapping, improvement in ventilation perfusion matching $(\dot{\mathrm{V}} / \mathrm{Q})$, a reduction in barotrauma, reduced respiratory muscle atrophy, and improved venous return augmenting cardiac output and improving renal perfusion. 46

It would also be remiss not to judge the introduction of IMV in light of the standard of care at the time. Tidal volumes of $12-15 \mathrm{~mL} / \mathrm{kg}$ were the norm, and even patienttriggered volume control breaths required a significant effort by the patient. The idea to interpose spontaneous breaths from a continuous flow source with mandatory breaths 
6-10 times/min, acting as true sigh breaths, seemed a plausible solution to constant flow volume-control ventilation and heavy sedation or paralysis. The interest was sufficient that an entire issue of INTERNational ANESTHESIOLOGY CLINICS was devoted to the topic of IMV in $1980 .{ }^{47}$

One suspects that Kirby and Downs, ${ }^{3,11}$ faced with the current paradigm of patients ventilated at $>20$ breaths/min, would lament the complete misunderstanding of the intent of IMV (ie, the lowest possible mandatory rate to support a patient with hypoxemic respiratory failure with PEEP maximized to restore lung volume and place the lung on a portion of the pressure volume curve that reduced the work of breathing). ${ }^{3,11}$ Weaning was rarely needed in this paradigm because the patient was on the lowest mandatory rate, as early as possible. It should also be noted that the supporters of IMV, very early on, used a room air CPAP trial to determine the suitability for extubation. ${ }^{48}$

The allure of IMV lives on in 2016 under other names: adaptive support ventilation, airway pressure release ventilation, and biphasic ventilation, modes that my colleague has described as potentially advantageous. ${ }^{6,49-51}$ Each of these is just another method to exploit the advantages of spontaneous breathing outside the IMV brand.

\section{The Importance of Spontaneous Breathing}

Distribution of Ventilation and Gas Exchange. Froese and Bryan ${ }^{52}$ published the seminal work on the importance of spontaneous breathing on the distribution of ventilation in 1974. In a remarkable trial of volunteers (“..three volunteer anesthetists of widely differing configuration, who were fully informed of the nature of the proposed study"), they studied the position and movement of the diaphragm during spontaneous breathing and mechanical ventilation during muscle paralysis. The widely differing configurations included a range of body mass index from 23 to $29 \mathrm{~kg} / \mathrm{m}^{2}$.

This work demonstrated that spontaneous breathing in an awake or anesthetized state resulted in the greatest displacement of diaphragmatic movement in the dependent position. This occurred despite the fact that intra-abdominal pressure was highest in the dependent lung. Following paralysis and positive-pressure ventilation, the diaphragmatic displacement was reversed. Movement of the diaphragm was cephalad with the largest change in the nondependent lung regions where intra-abdominal pressure was the least. Importantly, neither an increase in tidal volume nor the application of PEEP was able to correct the maldistribution of lung volume. This is often explained as the distribution of ventilation, following the path of least resistance. The phenomenon is more complicated than that, since gravity, regional lung compliance, pleural pressure

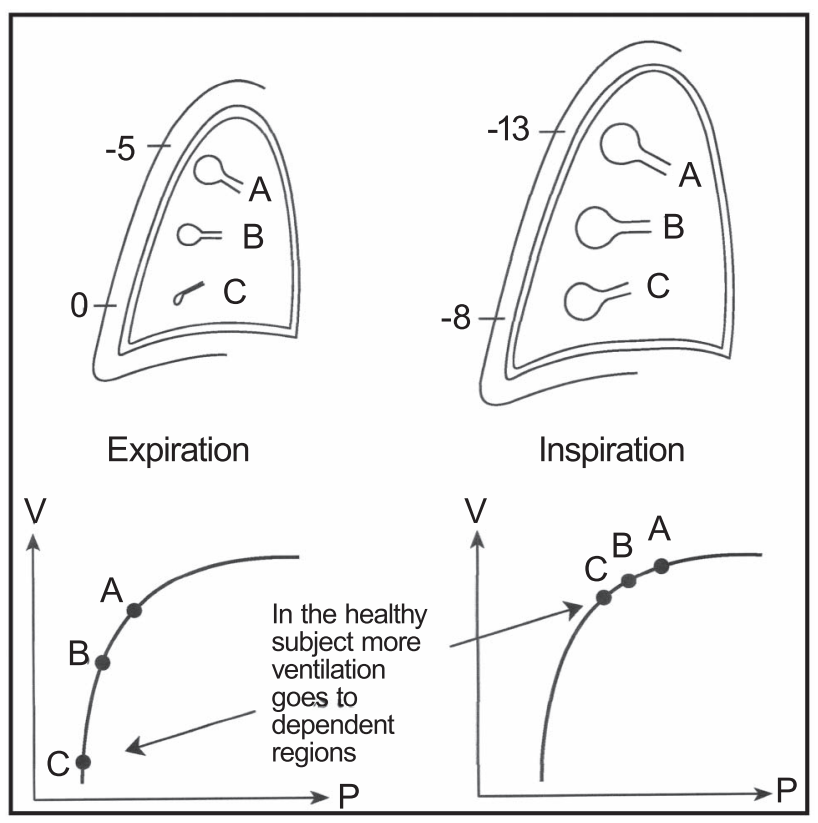

Fig. 6. Schematic drawing of alveolar sizes at upper (A), middle (B), and lower dependent $(C)$ lung regions at end expiration and end inspiration. Note the pleural pressure that approaches 0 in the lower part of the pleural space and the more negative pressure higher up. Lower panels show corresponding pressure $(P)$-volume (V) curves. From Reference 46, with permission.

gradients, and variations in expiratory lung volumes all contribute to the resulting distribution of ventilation. ${ }^{53,54}$

Regional differences in gas distribution are demonstrated in Figure 6. Under normal conditions, a greater volume of inspired gas is distributed to the dependent lung regions compared with non-dependent lung units. Uneven distribution is the result of the normal curve of the lung pressure-volume relationship. Transpulmonary pressure decreases from the apex to the base of the lung. Non-dependent lung regions have higher transpulmonary pressure than dependent lung regions, such that during inspiration, pleural pressure is reduced and dependent lung regions have a larger volume change for a similar transpulmonary pressure. In the mechanically ventilated patient, maldistribution of volume is exacerbated by heterogeneous lung disease (eg, ARDS), supine position, age, sex, body mass index, and paralysis. ${ }^{46}$

Following their pioneering work in volunteers, the Canadian group ${ }^{55}$ studied children undergoing anesthesia for a surgical procedure. They compared the dead space/tidal volume ratio $\left(\mathrm{V}_{\mathrm{D}} / \mathrm{V}_{\mathrm{T}}\right)$ during 3 methods of airway control and ventilation. Subjects were intubated and received controlled ventilation, were intubated with spontaneous breathing, or received mask anesthesia with spontaneous breathing. The study demonstrated that increases in tidal volume with positive-pressure ventilation failed to alter $\mathrm{V}_{\mathrm{D}} / \mathrm{V}_{\mathrm{T}}$, suggesting greater dead space from overdistention of al- 


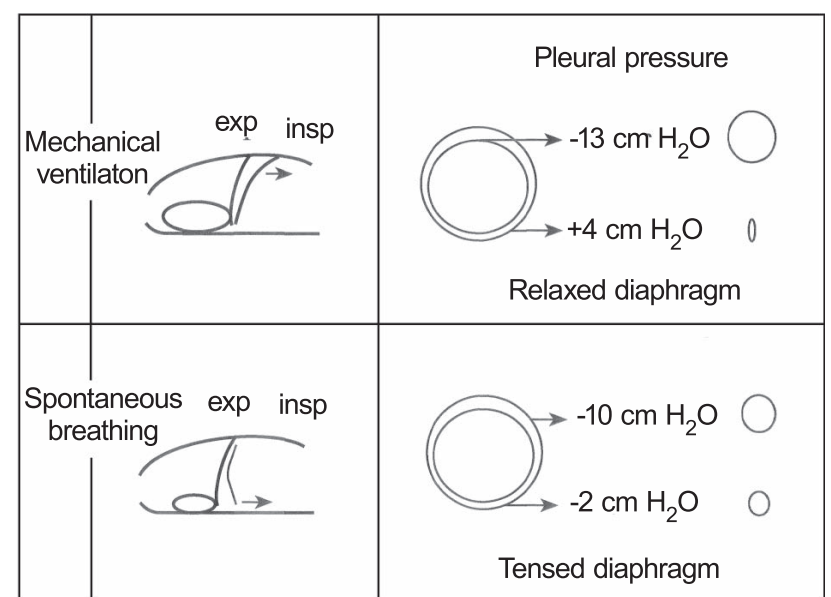

Fig. 7. Schematic of mechanisms behind the better recruitment of alveoli with spontaneous breathing. The left panels show the excursion of the diaphragm during mechanical ventilation and spontaneous breathing. Note the greater excursion in dorsal parts with spontaneous breathing. The right panels show the difference in the vertical pressure gradient during mechanical ventilation and spontaneous breathing, with a larger variation with mechanical ventilation and the potential of developing positive pleural pressure in the lower parts. This will promote collapse of alveoli. From Reference 46, with permission. Exp = expiratory; insp = inspiratory.

ready ventilated lung regions. Only during spontaneous ventilation did $\mathrm{V}_{\mathrm{D}} / \mathrm{V}_{\mathrm{T}}$ fall as breathing frequency slowed and tidal volume increased, suggesting improved matching of ventilation to areas of perfused lung.

Experiments in a porcine model have further defined the advantages of spontaneous breathing in enhancing ventilation perfusion relationships and oxygenation. ${ }^{56,57}$ Using both computed tomography and a $\gamma$ camera technique, one group demonstrated that lung injury with oleic acid resulted in a predictable fall in end-expiratory lung volume and oxygenation. Animals were either maintained on controlled ventilation or allowed to breathe up to $30 \%$ of the total minute volume spontaneously. The spontaneously breathing group had a marked increase in end-expiratory lung volume, a reduction in the amount of unaerated lung tissue, and a significant improvement in oxygenation. Measurements of $\dot{V} / \mathbf{Q}$ also improved as a consequence of greater dependent lung aeration, where gravity-dependent blood flow is greatest.

A schematic representation of the improved distribution of ventilation in the supine mechanically ventilated subject is shown in Figure 7. This is based on the work of Froese and Bryan ${ }^{52}$ and that of Roussos et al. ${ }^{58}$ Roussos et al ${ }^{58}$ demonstrated that with the active diaphragm (his term was "tensed"), the differences in pleural pressures between nondependent and dependent lung regions was smaller. As a result, the positive pressure seen with a relaxed diaphragm promotes alveolar collapse, whereas maintenance of diaphragmatic activity promotes lung aeration.
A number of animal trials have all demonstrated the positive impact of spontaneous breathing on $\dot{\mathrm{V}} / \dot{\mathrm{Q}}$ and gas exchange. ${ }^{59-62}$ These investigations were followed by clinical studies in subjects, demonstrating similar results. ${ }^{63-65}$ In each instance, the maintenance of spontaneous breathing resulted in improved gas exchange resulting from better $\dot{V} / \mathbf{Q}$ matching.

With respect to IMV or SIMV and the ability to improve gas exchange and promote recruitment of dependent lung regions, there can be no argument. Compared with CMV, maintenance of spontaneous breathing during IMV provides an anatomic and physiologic advantage.

Cardiovascular Advantages. Certain physiologic principles are unchanged by opinion or bias with respect to positive-pressure ventilation. Preeminent among these is that positive pressure increases intrathoracic pressure and reduces venous return, resulting in a decrease in preload and a fall in cardiac output. 66 Downs and others ${ }^{11,47}$ surmised that replacing mandatory breaths with spontaneous breaths would counteract this complication and, simply by reducing intrathoracic pressure, improve circulatory performance.

In a number of experimental ${ }^{61,62}$ and clinical studies, ${ }^{63,65-69}$ the reduction in intrathoracic pressure through the addition of spontaneous breathing has demonstrated improved venous return, enhanced cardiac output, and increased oxygen delivery. With IMV, this improvement results not only from simply reducing the rate of positive pressure breaths but from maintaining the intrathoracic pump mechanism whereby negative pressure generated during inspiration enhances venous return regardless of the level of PEEP. ${ }^{70,71}$ There are no comparisons with CMV in the literature that fail to demonstrate the superiority of IMV in improving cardiac performance. By maintaining improved cardiac output, IMV may reduce the need for fluid resuscitation and the use of vasopressors and decrease fluid accumulation in the lung seen with aggressive resuscitation.

\section{Liberation From Mechanical Ventilation}

Although IMV was in fact introduced as a method to facilitate weaning, $3,72,73$ the intended application of IMV in patients with hypoxemic respiratory failure was that weaning would begin on day 1 (ie, the lowest IMV rate that kept the spontaneous breathing frequency $<30$ breaths/ min was tolerated).

Studies evaluating IMV as a weaning technique have been inherently flawed by the arbitrary slow reduction in breathing frequency in 1-2-breath increments in a predetermined time frame. ${ }^{16,17,74}$ Patient selection is also important. Whereas Downs et $\mathrm{al}^{4}$ and others described the use of IMV for weaning in patients with chronic lung disease, our 
current understanding of respiratory muscle physiology, muscle fatigue, and air trapping suggests that IMV should be avoided in this population, although by replacing mandatory breaths with spontaneous breaths, air trapping may be diminished, and the patient can become more comfortable and synchronous. The ideal patient for initial ventilatory support and then termination of ventilatory support through a spontaneous breathing trial is the patient with hypoxemic respiratory failure, low lung volume, and an absence of preexisting chronic respiratory dysfunction.

\section{Acid-Base Balance}

One early proposed advantage of IMV was the avoidance of respiratory alkalosis. ${ }^{3,4}$ Respiratory alkalosis can occur with CMV and pressure support, resulting in periodic breathing and disturbed sleep cycles. ${ }^{75-77}$ The paper by Hudson et $\mathrm{al}^{26}$ evaluated subjects with respiratory alkalosis on CMV and transitioned subjects to IMV at half the assist control rate. Minute ventilation was lower with $\mathrm{IMV}$, but $\mathrm{CO}_{2}$ production was increased, resulting in equivalent values for $\mathrm{P}_{\mathrm{aCO}}{ }_{2}$. This is another study accomplished when tidal volumes of $10-15 \mathrm{~mL} / \mathrm{kg}$ were common. There was a modest but statistically insignificant fall in $\mathrm{pH}$ (from 7.51 to 7.48 ). The maintenance of the respiratory alkalosis following transition to IMV is troubling and perhaps was due to insufficient PEEP in the study by a group of investigators known to be cautious with the use of PEEP at that time. Failure to use PEEP in appropriate amounts to help reduce the work of breathing could have led to continued tachypnea. Although ignored in the early pages of this paper, Gallagher ${ }^{78}$ did demonstrate frequent respiratory alkalosis, complicating weaning from mechanical ventilation with CMV.

\section{The Work of Breathing}

Whereas the points earlier in this paper focus on the work of breathing during a single breath or from breath to breath, research in this area fails to acknowledge that simply increasing the mandatory IMV rate, thereby reducing the percentage of the minute ventilation required via spontaneous breathing, in fact reduces the work of breathing. Work of breathing during IMV is also impacted by choice of the patient population, appropriate application of PEEP, system for IMV delivery, and appropriate use of mandatory breath rate and size to assist in lung inflation and carbon dioxide removal.

IMV augments spontaneous breathing with mandatory breaths, which act as a sigh to remove carbon dioxide and prevent alveolar collapse. Paramount to the success of IMV is patient selection (ie, a patient with low lung volumes, tachypnea, hypoxemia, and normo- to hypocapnia). Under these conditions, the judicious use of PEEP to re- store end-expiratory lung volume and position the patient on the steep portion of the pressure-volume curve allows work of breathing to be managed. ${ }^{79}$ Application of IMV in patients with respiratory muscle fatigue, chronic lung disease, or neuromuscular disease is a misapplication of the technique. In these cases, a mode of support that rests fatigued muscles is called for. The failure of IMV in this instance is a failure of application.

Perhaps the worst problem to befall IMV was the introduction of intermittent demand ventilation (IDV) or demand valves for spontaneous breathing. ${ }^{8}$ This initial investigation consisted of several physicians breathing on a modified MA-1 with the ability to provide IDV (SIMV) versus IMV. All of the physicians in the study agreed that the IDV (SIMV) was more desirable, not exactly translational science. In the ensuing years, evaluations of the work of breathing of SIMV systems demonstrated significant advantages of continuous flow systems. ${ }^{80-84}$ In fact, the 2 authors of this paper have spent good parts of our academic careers comparing the work of breathing imposed by ventilators. And although modern day ventilators have sophisticated systems for triggering and cycling the spontaneous breath, asynchrony in timing remains an issue. Continuous flow systems could complicate monitoring, obfuscate humidifiers of the day, augment tidal volume, and complicate setup. However, the early switch to demand valve systems was not an advantage for the patient, just for the caregiver. Of note, the only investigation to evaluate the role of synchronizing mandatory breaths during IMV failed to show any advantage of SIMV over IMV. .5

\section{Asynchrony}

Asynchrony is a common problem during CMV, PSV, and IMV..$^{35,36,41}$ However, the incidence of asynchrony during assist control demonstrated by Thille et $\mathrm{al}^{35}$ and SIMV as reported by de Wit et $\mathrm{al}^{36}$ is essentially the same. In both cases, missed triggers predominate, a function of patient population (COPD) and excessive ventilatory support. The paper by Robinson et $\mathrm{al}^{41}$ evaluating asynchrony in trauma subjects, many receiving SIMV, finds a similar incidence of asynchrony with none of the negative consequences (prolonged ICU stay, mortality, etc). More than half of our asynchrony events were stacking of adaptive pressure breaths during SIMV + PSV. Figure 8 demonstrates this phenomenon. The opinion of the authors was that this is unique to this ventilator and this mode and that in the volume control mode, this would not happen. The only factor to correlate with this type of asynchrony was the set mandatory rate. The higher the mandatory rate, the greater the risk of asynchrony. Downs and Kirby would probably admonish us to be true to the original principles. 


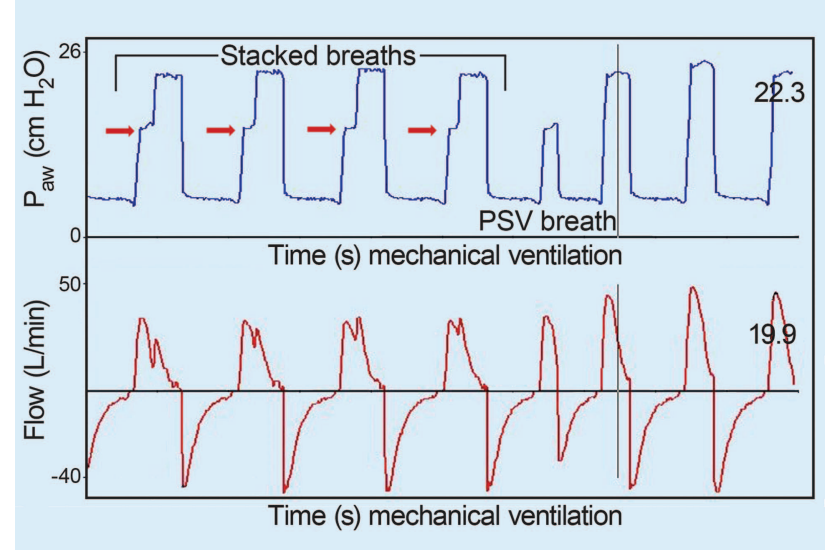

Fig. 8. Screenshot of breath-stacking of mandatory breaths on top of spontaneous breaths during adaptive pressure ventilation in the synchronized intermittent mandatory ventilation mode. Note that since breaths are pressure-limited, the absolute pressure is limited but inspiratory time is prolonged; hence, volume is increased. PSV $=$ pressure support ventilation.

\section{Use of IMV}

Although the use of IMV is declining ${ }^{42,43}$ precipitously, it is interesting to note that at one time, IMV was the most frequently applied mode for weaning in the United States. ${ }^{86}$ Interestingly, the likelihood of being ventilated with IMV correlates with geography. If you live in the United States, you are more likely to be placed on IMV. IMV lives on in other modes (adaptive support ventilation, airway pressure release ventilation, and biphasic ventilation), each maintaining spontaneous breathing as an important feature. The calls for the removal of IMV are premature. Routine use of small tidal volumes, which represent the standard of care, however, render the concept of IMV less attractive, since the use of mandatory breaths as "sighs" no longer fulfills that role at $6 \mathrm{~mL} / \mathrm{kg}$.

\section{Outcomes}

Every head-to-head comparison of IMV and CMV has concluded that there are no differences in outcomes. ${ }^{13,15,87-89}$ The truth of the matter is that in large trials, IMV is as useful as CMV, hardly a mandate to eliminate the use of IMV. Perhaps a re-evaluation and re-education of the appropriate application of IMV is the real mandate.

\section{Conclusions}

In a paper, such as this, where the pro and con must be defended with vigor, regardless of the viewpoints of the authors, the evidence for the continued use of IMV or SIMV is on life support. Spontaneous breathing has many advantages. In 2016, however, these advantages can be obtained through other techniques, such as proportional assist ventilation (PAV) and neurally adjusted ventilatory assist (NAVA), while better supporting the patient's work of breathing. IMV clearly demonstrates no evidence to speed ventilator discontinuation. In patients with respiratory muscle fatigue or respiratory muscle dysfunction, IMV may, in fact, prolong weaning, bringing back the days when IMV was referred to as "intermittent respiratory failure." Our practice must be informed by evidence, and at present the evidence for continued use of IMV outside of very special circumstances cannot be supported.

\section{REFERENCES}

1. Kirby RR, Robison EJ, Schulz J, DeLemos R. A new pediatric volume ventilator. Anesth Analg 1971;50(4):533-537.

2. Kirby R, Robison E, Schulz J, DeLemos RA. Continuous-flow ventilation as an alternative to assisted or controlled ventilation in infants. Anesth Analg 1972;51(6):871-875.

3. Downs JB, Klein EF Jr, Desautels D, Modell JH, Kirby RR. Intermittent mandatory ventilation: a new approach to weaning patients from mechanical ventilation. Chest 1973;64(3):331-335.

4. Downs JB, Block AJ, Vennum KB. Intermittent mandatory ventilation in the treatment of patients with chronic obstructive pulmonary disease. Anesth Analg 1974;53(3):437-443.

5. Sassoon CH. Intermittent mandatory ventilation. In Tobin MJ, editor. Mechanical ventilation: principles and practice. 3 rd edition. New York: McGraw-Hill; 2014: 201-220.

6. Kacmarek RM. The mechanical ventilator: past, present, and future. Respir Care 2011;56(8):1170-1180.

7. Mushin WW, Rendell-Baker L, Thompson PW, Mapleson WW. Automatic ventilation of the lungs. 3rd edition. London: Blackwell Scientific Publishers; 1980: 354-360.

8. Shapiro BA, Harrison RA, Walton JR, Davison R. Intermittent demand ventilation (IDV): a new technique for supporting ventilation in critically ill patients. Respir Care 1976;21(6):521-525.

9. Prakash O, Meij S. Cardiopulmonary response to inspiratory pressure support ventilation. Chest 1985;88(3):403-408.

10. MacIntyre NR. Respiratory function during pressure support ventilation. Chest 1986;89(5):677-683.

11. Downs JB, Perkins HM, Modell JH. Intermittent mandatory ventilation: an evaluation. Arch Surg 1974;109(4):519-523.

12. Santak B, Radermacher P, Sandmann W, Falke KJ. Influence of SIMV plus pressure support on VA/Q distribution during postoperative weaning. Intensive Care Med 1991;17(3):136-140.

13. Groeger JS, Levinson MR, Carlon GC. Assist control versus synchronized intermittent mandatory ventilation during acute respiratory failure. Crit Care Med 1989;17(7):607-612.

14. Shelledy DC, Rau JL, Thomas-Goodfellow L. A comparison of the effects of assist-control, SIMV, and SIMV plus pressure support on ventilation, oxygen consumption, and ventilation equivalent. Heart Lung 1995;24(1):67-75.

15. Tassaux D, Dalmas E, Gratadour P, Jolliet P. Patient-ventilator interactions during partial ventilatory support: A preliminary study comparing the effects of adaptive support ventilation with synchronized intermittent mandatory ventilation plus inspiratory pressure support. Crit Care Med 2002;30(4):801-807.

16. Esteban A, Frutos F, Tobin MJ, Alía I, Solsona JF, Valverdú I, et al. A comparison of four methods of weaning patients from mechanical ventilation: Spanish lung failure collaborative group. N Engl J Med 1995;332(5):345-350. 
17. Brochard L, Rauss A, Benito S, Conti G, Mancebo J, Rekik N, et al. Comparison of three methods of gradual withdrawal from ventilatory support during weaning from mechanical ventilation. Am J Respir Crit Care Med 1994;150(4):896-903.

18. Ely EW, Baker AM, Dunagan DP, Burke HL, Smith AC, Kelly PT, et al. Effect on the duration of mechanical ventilation of identifying patients capable of breathing spontaneously. N Engl J Med 1996; 335(25):1864-1869.

19. Kollef MH, Shapiro SD, Silver P, St John RE, Prentice D, Sauer S, et al. A randomized controlled trial of protocol driven vs. physiciandirected weaning from mechanical ventilation. Crit Care Med 1997; 25(4):567-574.

20. Esteban A, Alia I, Gordo F, Fernandez R, Solsona JF, Vallverdú I, et al. Extubation outcome after spontaneous breathing trials with T-piece or pressure support ventilation: Spanish Lung Failure Collaborative group. Am J Respir Crit Care Med 1997;156(2 Pt 1):459465.

21. Horst HM, Mouro D, Hall-Jenssens RA, Pamukov N. Decrease in ventilation time with a standardized weaning process. Arch Surg 1998;133(5):483-488; discussion 488-489.

22. Esteban A, Alía I, Tobin MJ, Gil A, Gordo F, Vallverdú I, et al. Effect of spontaneous breathing trial duration on outcome of attempts to discontinue mechanical ventilation: Spanish Lung Failure Collaborative group. Am J Respir Crit Care Med 1999;159(2):512518.

23. Marelich GP, Murin S, Battistella F, Inciardi J, Vierra T, Roby M. Protocol weaning of mechanical ventilation in medical and surgical patients by respiratory care clinicians and nurses: effect on weaning time and incidence of ventilator associated pneumonia. Chest 2000; 118(2):459-467.

24. Krishnan JA, Moore D, Robeson C, Rand CS, Fessler HE. A prospective controlled trial of a protocol based strategy to discontinue mechanical ventilation. Am J Respir Crit Care Med 2004;169(6): 673-678.

25. MacIntyre NR, Cook DJ, Ely EW, Epstein SK, Fink JB, Heffner JE, et al. Evidence based guidelines for weaning and discontinuing ventilatory support: a collective task force facilitated by the American College of Chest Physicians, the American Association for Respiratory Care and the American College of Critical Care Medicine. Chest 2001;120(6 Suppl):375S-395S.

26. Hudson LD, Hurlow RS, Craig KC, Pierson DJ. Does intermittent mandatory ventilation correct respiratory alkalosis in patients receiving assisted mechanical ventilation? Am Rev Respir Dis 1985;132(5): 1071-1074.

27. Weiss JW, Rossing TH, Ingram RH Jr. Effect of intermittent mandatory ventilation on respiratory drive and timing. Am Rev Respir Dis 1983;127(6):705-708.

28. Marini JJ, Smith TC, Lamb VJ. External work output and force generation during synchronized intermittent mechanical ventilation: effect of machine assistance on breathing effort. Am Rev Respir Dis 1988;138(5):1169-1179.

29. Imsand C, Feihl F, Perret C, Fitting JW. Regulation of inspiratory neuromuscular output during synchronized intermittent mechanical ventilation. Anesthesiology 1994;80(1):13-22.

30. Kapasi M, Fujino Y, Kirmse M, Catlin EA, Kacmarek RM. Effort and work of breathing in neonates during assisted patient-triggered ventilation. Pediatr Crit Care Med 2001;2(1):9-16.

31. Uchiyama A, Imanaka H, Taenaka N, Nakano S, Fujino Y, Yoshiya I. Comparative evaluation of diaphragmatic activity during synchronized intermittent mandatory ventilation in an animal model. Am J Respir Crit Care Med 1994;150(6):1564-1568.

32. Beck J, Tucci M, Emeriaud G, Lacroix J, Sinderby C. Prolonged neural expiratory time induced by mechanical ventilation in infants. Pediatr Res 2004;55(5):747-754.
33. Leung P, Jubran A, Tobin MJ. Comparison of assisted ventilator modes on triggering, patient effort and dyspnea. Am J Respir Crit Care Med 1997;155(6):1940-1948.

34. Eldridge FL. Maintenance of respiration by central neural feedback mechanisms. Fed Proc 1977;36(10):2400-2404

35. Thille AW, Rodriguez P, Cabello B, Lellouche F, Brochard L. Patient-ventilator asynchrony during assisted mechanical ventilation. Intensive Care Med 2006;32(10):1515-1522.

36. de Wit M, Pedram S, Best AM, Epstein S. Observational study of patient-ventilator asynchrony and its relationship to sedation level. J Crit Care 2009;24(1):74-80.

37. Blanch L, Villagra A, Sales B, Montanya J, Lucangelo U, Luján M, et al. Asynchronies during mechanical ventilation are associated with mortality. Intensive Care Med 2015;41(4):633-641.

38. Kacmarek RM, Villar J, Blanch L. Why use anything but a standard spontaneous breathing trial to determine readiness for ventilator discontinuation? Respir Care 2015;60(11):1705-1707.

39. Chanques G, Kress JP, Pohlman A, Patel S, Poston J, Jaber S, Hall JB. Impact of ventilator adjustment and sedation-analgesia practices on severe asynchrony in patients ventilated in assist-control mode. Crit Care Med 2013;41(9):2177-2187.

40. Pohlman MC, McCallister KE, Schweickert WD, Pohlman AS, Nigos CP. Excessive tidal volume from breath stacking during lungprotective ventilation for acute lung injury. Crit Care Med 2008; 36(11):3019-3023.

41. Robinson BRH, Blakeman TC, Toth P, Hanseman DJ, Mueller E Branson RD. Patient-ventilator asynchrony in a traumatically injured population. Respir Care 2013;58(11):1847-1855.

42. Esteban A, Anzueto A, Alía I, Gordo F, Apezteguía C, Pálizas F, et al. How is mechanical ventilation employed in the intensive care unit? an international utilization review. Am J Respir Crit Care Med 2000;161(5):1450-1458.

43. Esteban A, Ferguson ND, Meade MO, Frutos-Vivar F, Apezteguia C, Brochard L, Raymondos K, Nin N, Hurtado J, Tomicic V, González M, Elizalde J, Nightingale P, Abroug F, Pelosi P, Arabi Y, Moreno R, Jibaja M, D'Empaire G, Sandi F, Matamis D, Montañez AM, Anzueto A; VENTILA Group. Evolution of mechanical ventilation in response to clinical research. Am J Respir Crit Care Med. 2008 Jan 15;177(2):170-7.

44. Ghamloush M, Hill NS. Synchronized intermittent mandatory ventilation: time to send this workhorse out to pasture. Respir Care 2013;58(11):1992-1994.

45. Petty TL. Intermittent mandatory ventilation-reconsidered. Crit Care Med 1981;9(8):620-621.

46. Hedenstierna G, Lichtwarck-Aschoff M. Interfacing spontaneous breathing and mechanical ventilation. Minerva Anestesiol 2006;72(4): 183-198.

47. Kirby RR, Graybar GB. Intermittent mandatory ventilation. Int Anesthesiol Clin 1980;18(2):1-189.

48. DeHaven CB Jr, Hurst JM, Branson RD. Evaluation of two different extubation criteria: attributes contributing to success. Crit Care Med 1986;14(2):92-94.

49. Sulemanji DS, Marchese A, Wysocki M, Kacmarek RM. Adaptive support ventilation with and without end-tidal $\mathrm{CO}_{2}$ closed loop control versus conventional ventilation. Intensive Care Med 2013;39(4): 703-710.

50. Sulemanji D, Marchese A, Garbarini P, Wysocki M, Kacmarek RM. Adaptive support ventilation: an appropriate mechanical ventilation strategy for acute respiratory distress syndrome? Anesthesiology 2009;111(4):863-870.

51. Kacmarek RM. Ventilatory adjuncts. Respir Care 2002;47(3):319330; discussion 330-333.

52. Froese AB, Bryan AC. Effects of anesthesia and paralysis on diaphragmatic mechanics in man. Anesthesiology 1974;41(3):242-255. 
53. Milic-Emili J, Henderson JAM, Dolovich MB, Trop D, Kaneko K. Regional distribution of inspired gas in the lung. J Appl Physiol 1966;21(3):749-759.

54. Kaneko K, Milic-Emili J, Dolovich MB, Dawson A, Bates DV. Regional distribution of ventilation and perfusion as a function of body position. J Appl Physiol 1966;21(3):767-777.

55. Rose DK, Froese AB. Changes in respiratory pattern affect dead space/tidal volume ratio during spontaneous but not during controlled ventilation: a study in pediatric patients. Anesth Analg 1980; 59(5):341-349.

56. Neumann P, Wrigge H, Zinserling J, Hinz J, Maripuu E, Andersson LG, et al. Spontaneous breathing affects the spatial ventilation and perfusion distribution during mechanical ventilatory support. Crit Care Med 2005;33(5):1090-1095.

57. Wrigge H, Zinserling J, Neumann P, Defosse J, Magnusson A, Putensen C, Hedenstierna G. Spontaneous breathing improves lung aeration in oleic acid-induced lung injury. Anesthesiology 2003; 99(2):376-384.

58. Roussos CS, Fukuchi Y, Macklem PT, Engel LA. Influence of diaphragmatic contraction on ventilation distribution in horizontal man. J Appl Physiol 1976;40(3):417-424.

59. Putensen C, von Spiegel T, Hering R, Stüber F, Zinserling J. Effect of different ventilatory support modalities on the ventilation to perfusion distributions. Acta Anaesthesiol Scand Suppl 1997;111:119122.

60. Putensen C, Räsänen J, López FA. Interfacing between spontaneous breathing and mechanical ventilation affects ventilation-perfusion distributions in experimental bronchoconstriction. Am J Respir Crit Care Med 1995;151(4):993-999.

61. Putensen C, Räsänen J, López FA, Downs JB. Effect of interfacing between spontaneous breathing and mechanical cycles on the ventilation-perfusion distribution in canine lung injury. Anesthesiology 1994;81(4):921-930.

62. Putensen C, Räsänen J, López FA. Ventilation-perfusion distributions during mechanical ventilation with superimposed spontaneous breathing in canine lung injury. Am J Respir Crit Care Med 1994; 150(1):101-108.

63. Hering R, Peters D, Zinserling J, Wrigge H, von Spiegel T, Putensen C. Effects of spontaneous breathing during airway pressure release ventilation on renal perfusion and function in patients with acute lung injury. Intensive Care Med 2002;28(10):1426-1433.

64. Kuhlen R, Putensen C. Maintaining spontaneous breathing efforts during mechanical ventilatory support. Intensive Care Med 1999; 25(11):1203-1205.

65. Putensen C, Mutz NJ, Putensen-Himmer G, Zinserling J. Spontaneous breathing during ventilatory support improves ventilation-perfusion distributions in patients with acute respiratory distress syndrome. Am J Respir Crit Care Med 1999;159(4 Pt 1):1241-1248.

66. Pinsky MR. Determinants of pulmonary arterial blood flow variation during respiration. J Appl Physiol 1984;56(5):1237-1245.

67. Falkenhain SK, Reilley TE, Gregory JS. Improvement in cardiac output during airway pressure release ventilation. Crit Care Med 1992;20(9):1358-1360.

68. Downs JB, Douglas ME, Sanfelippo PM, Stanford W, Hodges MR. Ventilatory pattern, intrapleural pressure, and cardiac output. Anesth Analg 1977;56(1):88-96.

69. Sladen RN, Jenkins LC. Intermittent mandatory ventilation and controlled mechanical ventilation without positive end-expiratory pressure following cardio-pulmonary bypass. Can Anaesth Soc J 1978; 25(3):166-172.
70. Kirby RR, Perry JC, Calderwood HW, Ruiz BC, Lederman DS. Cardiorespiratory effects of high positive end-expiratory pressure. Anesthesiology 1975;43(5):533-539.

71. Kirby RR, Downs JB, Civetta JM, Modell JH, Dannemiller FJ, Klein EF, Hodges M. High level positive end expiratory pressure (PEEP) in acute respiratory insufficiency. Chest 1975;67(2):156-163.

72. Downs JB, Douglas ME. Intermittent mandatory ventilation and weaning. Int Anesthesiol Clin 1980;18(2):81-95.

73. Downs JB, Perkins HM, Sutton WW. Successful weaning after five years of mechanical ventilation. Anesthesiology 1974;40(6):602-603.

74. Schachter EN, Tucker D, Beck GJ. Does intermittent mandatory ventilation accelerate weaning? JAMA 1981;246(11):1210-1214.

75. Alexopoulou C, Kondili E, Plataki M, Georgopoulos D. Patientventilator synchrony and sleep quality with proportional assist and pressure support ventilation. Intensive Care Med 2013;39(6):10401047.

76. Wrigge H, Golisch W, Zinserling J, Sydow M, Almeling G, Burchardi H. Proportional assist versus pressure support ventilation: effects on breathing pattern and respiratory work of patients with chronic obstructive pulmonary disease. Intensive Care Med 1999; 25(8):790-798.

77. Meza S, Mendez M, Ostrowski M, Younes M. Susceptibility to periodic breathing with assisted ventilation during sleep in normal subjects. J Appl Physiol 1998;85(5):1929-1940.

78. Gallagher TJ. Metabolic alkalosis complicating weaning from mechanical ventilation. South Med J 1979;72(7):786-787.

79. Downs JB, Stock MC, Tabeling B. Intermittent mandatory ventilation (IMV): a primary ventilatory support mode. Ann Chir Gynaecol Suppl 1982;196:57-63.

80. Hillman DR, Breakey JN, Lam YM, Noffsinger WJ, Finucane KE. Minimizing work of breathing with continuous positive airway pressure and intermittent mandatory ventilation: an improved continuous low-flow system. Crit Care Med 1987;15(7):665-670.

81. Mecklenburgh JS, Latto IP, Al-Obaidi TA, Swai EA, Mapleson WW. Excessive work of breathing during intermittent mandatory ventilation. Br J Anaesth. 1986;58(9):1048-1054.

82. Christopher KL, Neff TA, Bowman JL, Eberle DJ, Irvin CG, Good JT Jr. Demand and continuous flow intermittent mandatory ventilation systems. Chest 1985;87(5):625-630.

83. Cox D, Niblett DJ. Studies on continuous positive airway pressure breathing systems. Br J Anaesth 1984;56(8):905-911.

84. Henry WC, West GA, Wilson RS. A comparison of the oxygen cost of breathing between a continuous-flow CPAP system and a demand-flow CPAP system. Respir Care 1983;28(10):1273-1281.

85. Heenan TJ, Downs JB, Douglas ME, Ruiz BC, Jumper L. Intermittent mandatory ventilation: is synchronization important? Chest 1980; 77(5):598-602.

86. Venus B, Smith RA, Mathru M. National survey of methods and criteria used for weaning from mechanical ventilation. Crit Care Med 1987;15(5):530-533.

87. Luo J, Wang MY, Liang BM, Yu H, Jiang FM, Wang T, et al. Initial synchronized intermittent mandatory ventilation versus assist/control ventilation in treatment of moderate acute respiratory distress syndrome: a prospective randomized controlled trial. J Thorac Dis 2015; 7(12):2262-2273.

88. Ortiz G, Frutos-Vivar F, Ferguson ND, Esteban A, Raymondos K, Apezteguía C, et al. Chest 2010;137(6):1265-1277.

89. El-Khatib M, Bou-Khalil P, Zeineldine S, Kanj N, Abi-Saad G, Jamaleddine G. Metabolic and respiratory variables during pressure support versus synchronized intermittent mandatory ventilation. Respiration 2009;77(2):154-159. 


\section{Discussion}

Hess: The one place where IMV might have a role, as you pointed out in your last slide, is to give a periodic sigh. There are now a number of papers, one is a paper in Critical Care Medicine by Mauri et al, ${ }^{1}$ who use biphasic positive airway pressure every $0.5-2 \mathrm{~min}$ to raise the pressure up to $35 \mathrm{~cm} \mathrm{H}_{2} \mathrm{O}$ for 3-4 s. It's a variation on IMV or airway pressure release ventilation or both of those things. They report that it improves alveolar recruitment, shunt, oxygenation, and so forth. I can say anecdotally that I've tried it in a few patients and was underwhelmed, but it might be something we should keep in mind.

MacIntyre: I wrote the editorial for that paper ${ }^{1}$ and they gave an awful lot of these sigh breaths. When they were doing 2 sigh breaths/min, they were providing 34 or $35 \%$ of the minute ventilation with $\mathrm{V}_{\mathrm{T}}$ levels and pressures that most of us would consider excessive. That worried me a lot. They had very low PEEP levels in that trial. I think if you have a low PEEP situation, recruitment maneuvers and sigh breaths are going to look a lot better than if you had a more aggressive PEEP strategy.

Hess: Which might explain why I have been underwhelmed the few times I've tried this.

Branson: The guys who invented IMV considered those 2 or 3 breaths/min as a sigh to recruit the lung. They weren't really looking at it as a method to maintain minute ventilation.

MacIntyre: When the number of sighs exceed $50 \%$ of the minute ventilation is it still a sigh?

Branson: I think there's a lot to that issue. The use of these large volume breaths and I've heard the IMV guys say the average frequency in the ARDSNet trial ${ }^{2}$ was 35 breaths/min.
That's 50,000 breaths/d. If you're on an IMV rate of 6, you have fewer than 10,000 breaths in a day. Somebody showed yesterday that it's not just the stretch but how many times you stretch the lung that matters. What if you had an approach that did a sigh twice a minute but the rest of the time you had low $\mathrm{V}_{\mathrm{T}}$ and aggressive PEEP? Clearly, we've already seen the history of this mechanical ventilation idea if you're in the OR. If and they notice during chest surgery that the FRC (functional residual capacity) falls and say let's give a sigh breath to reverse this problem. The sigh breath described was the anesthesiologist grabbing the bag and squeezing it with both hands up to a pressure of 40 $\left(\mathrm{cm} \mathrm{H}_{2} \mathrm{O}\right)$ and holding it there for a minute. That translated into low $\mathrm{V}_{\mathrm{T}}$ levels, consistent monotonous $\mathrm{V}_{\mathrm{T}}$ levels are bad. In the OR, you get 10 $15 \mathrm{~mL} / \mathrm{kg}$, and that migrated over into the ICU. Well, when you're in the ICU at $10-15 \mathrm{~mL} / \mathrm{kg}$, giving a sigh breath was a waste of time because virtually every breath was a sigh breath. Now that we've gone down to $4-6 \mathrm{~mL} / \mathrm{kg}$, the sigh breath may now be useful again. It's all about how we manage the airway pressures.

\section{MacIntyre: Depending on-}

Branson: Yes. PEEP, breath size, it all matters in whether a technique does or doesn't work.

Marini: It is true that when comparing the triggered breath with the surrounding spontaneous breaths at any given level of SIMV, the efforts are very similar. And that probably gives rise to asynchrony; one time you get a big breath of fixed length, and the next time you're pretty much on your own or with some lower level of pressure support. But as you give more and more machine-set breaths/min, the vigor of breathing diminishes. It can be an effective weaning mode if used carefully in an automated way. I'm not advocating this, I'm just saying that it's been suboptimally used in some of the published work. And I certainly agree with the sighing and disruption of monotony that it provides. SIMV is occasionally helpful for patients who cannot be ventilated easily because they have unstable drive to breathe-for example, awakening from sedation, when some get chaotic and then they fall asleep. You then have a very wide variation in ventilatory drive. Periodically giving 4 SIMV backup breaths tends to make the patient a little safer to manage-at least they don't go from all to nothing at all. The last thing I'd say is that variation in breath size might be helpful, at least theoretically. You alluded to this, Rich. The monotonous, consistent breath support that we give may not be natural. We may periodically need variation to keep our lungs healthy and uniformly recruited. You can call it biologically variable ventilation, or whatever, but SIMV kind of mimics that if you think about it, providing some bigger breaths and some smaller breaths. It therefore could have a positive physiologic rationale. Again, I don't advocate SIMV for weaning - we have better options. But it can be used effectively in that way, and it may have some advantages in highly selected situations. I don't think we ought to throw it out completely.

Kacmarek: Why not put those patients on PAV or NAVA and let their respiratory center dictate the variability instead of us trying to select for them what $\mathrm{V}_{\mathrm{T}}$ and what frequency that variability should occur? I agree there are patients, as you've said, but we have modes of ventilation that do a much better job today than SIMV in accommodating that type of breathing pattern.

Marini: Point well taken. If you have a ventilator that can provide NAVA or PAV+, you may do well with that. I still think you have the question of how do you back those people up when they're on PAV or NAVA. 
MacIntyre: You don't have to do NAVA or PAV. Pressure support lets patients pick the $\mathrm{V}_{\mathrm{T}}$ levels and frequency they want as well, and it's a lot simpler, cheaper, and more readily available.

Kacmarek: But you're more likely to get the large $V_{T}$ John is referring to with pressure support as compared with PAV or NAVA. Both of them have backup ventilation if the patient goes apneic; you can set it for a short period.

MacIntyre: You can do that with pressure-continuous mandatory ventilation. Just set the frequency to be 2 or 4 as a backup rate, and the rest are patient-triggered so that they can manipulate the frequency and $\mathrm{V}_{\mathrm{T}}$. You're just setting inspiratory time with that mode.

Kacmarek: What we're both saying is that we have alternate modes that do a better job. And that the problems with SIMV outweigh the potential benefit of utilizing it - for me, in any patient—-today.

Marini: They require less surveillance than SIMV, but there's nothing intrinsically wrong with SIMV other than that fact that you have to be there to manage and monitor it. I think advocates are used to doing that.

Kacmarek: The reality at the bedside is there's not that moment-tomoment monitoring.

Marini: We don't use it either, only very rarely in selected patients.
Kacmarek: They still use it in cardiac surgical patients, although we've gotten them to move to pressure support as soon as the patient starts making aggressive inspirations. But they come out of the OR on SIMV all the time. In our neonatal unit, even though we studied it in that same neonatal unit, they still use SIMV. ${ }^{3}$

Kallet: I absolutely agree, I think one of the things we're saying is it's not necessarily the mode. The problem is how the mode is used. I'm not quite as old as you guys, but I came into Respiratory Care during the early years of IMV. If I recall, the year that IMV was invented was also when you had the assist mechanism on IMV-they came up with that in the "70s. So at the same time that they allowed for assisted mechanical ventilation was the time when other clinicians were saying we need to do something different than this.

Kacmarek: When did the MA-1 come out?

* Masferrer: 1967.

Kacmarek: That was the only ventilator with true assisted ventilation.

Kallet: I think it took them a few years to adapt the MA-1 to have that mechanism. We use IMV for patients with a low minute ventilation demand but who are very alkalotic. There are very few patients where it works well. We use intermittent mandatory ventilation for patients who have a respiratory drive that is variable or drug

* Ray Masferrer RRT FAARC, Managing Editor, RESPIRATORY CARE. overdose, and it prevents the alarms from going off. That's a solution for a small percentage of patients. To reiterate, I think a lot of it is how the mode is used. Two breaths every $4 \mathrm{~h}$ it got worse when we added pressure to that, where the pressure support breaths have higher pressure and larger volume than the IMV breaths. In terms of weaning, it was how clinicians were using it more than the mode. One of the greatest quips about IMV I heard from John Murry; he called it intermittent mandatory respiratory distress.

Kacmarek: I think that's a good name for it.

Branson: My big concern now is I see people with these low $\mathrm{V}_{\mathrm{T}}$ levels still wanting to use IMV, so they set the IMV frequency at 20. Try to breathe on your own in between 20 breaths/min; it's not very easy. So then you walk up to the ICU and go through their history, and in $3 \mathrm{~d}$, the patient hasn't taken a spontaneous breath. It's called IMV, but it's acting exactly like CMV. That is a major problem.

\section{References}

1. Mauri T, Eronia N, Abbruzzese C, Marcolin R, Coppadoro A, Spadaro S, et al. Effects of sigh on regional lung strain and ventilation heterogeneity in acute respiratory failure patients undergoing assisted mechanical ventilation. Crit Care Med 2015; 43(9): 1823-1831.

2. The ARDS Network. Ventilation with lower tidal volumes as compared with traditional tidal volumes for acute lung injury and the ARDS. N Engl J Med 2000;342(18):13011308.

3. Kapasi M, Fujino Y, Kirmse M, Catlin EA, Kacmarek RM. Effort and work of breathing in neonates during assisted, patient triggered ventilation. Pediatr Crit Care Med 2001;2(1):9-16. 